\title{
Assessment of climatically suitable area for Syrmaticus reevesii under climate change
}

\author{
Xiao Feng ${ }^{1,2}$, Congtian Lin ${ }^{1}$, Huijie Qiao ${ }^{1}$, Liqiang $\mathrm{Ji}^{1, *}$ \\ ${ }^{1}$ Key Laboratory of Animal Ecology and Conservation Biology, Institute of Zoology, Chinese Academy of Sciences, \\ Beijing 100101, PR China \\ ${ }^{2}$ Present address: Department of Zoology, Oklahoma State University, Stillwater, OK 74074, USA
}

\begin{abstract}
Global climate change is one of the major threats to biodiversity. Global warming caused by the excess emission of greenhouse gases affects the distribution and physiology of species, and threatens their survival. Thus, predicting and evaluating the consequences of changing climates on species' distributions is important for biodiversity conservation. The goal of our study was to assess the influence of future climate scenarios on the extent and geographic location of climatically suitable areas for Reeves's pheasant Syrmaticus reevesii, a species endemic to China, using geographic information systems and ecological niche modeling techniques. We compared model prediction under present climate with the species' historical range and land-cover data, both of which enable a plausible assessment of present-day climatically suitable areas for the species. The areas predicted suitable under future climates showed differences among emission scenarios, but several common trends emerged. Specifically, our results indicated that future climatically suitable area for $S$. reevesii would decrease and shift to higher altitudes, and the geographic centroids of the climatically suitable areas would mainly move northwest. Additionally, we assessed future changes of climatically suitable areas in the nature reserves where $S$. reevesii is known to occur, and provided suggestions for conserving the species under climate change scenarios.
\end{abstract}

KEY WORDS: Climate change $\cdot$ Potential distribution $\cdot$ Maxent $\cdot$ Reeves's pheasant

\section{INTRODUCTION}

Species' responses to global climate change have been one of the most investigated issues in the field of ecology in recent years (Walther et al. 2002, Thomas et al. 2004, Peterson et al. 2008b). According to the Intergovernmental Panel on Climate Change (IPCC), the global climate is getting warmer, and extreme weather events (droughts, floods, storms, and heat waves) are becoming more frequent (Solomon et al. 2007). Climate change can affect species' habitats by altering abiotic factors, which in turn affect biotic interactions and distribution patterns of species (Walther et al. 2002). Under climate change, areas previously unsuitable may become suitable, while current suit-

*Corresponding author: ji@ioz.ac.cn able areas may become less appropriate for a species (Williams et al. 2007, Liu et al. 2011, Hu \& Liu 2014, Markovic et al. 2014). Previous studies showed that the climate changes of the 20th century have already affected the size, range, and elevation of many species' distributions, such as arctic shrubs (Sturm et al. 2001), butterflies (Parmesan et al. 1999, Boggs et al. 2003), birds (Sun \& Zhang 2000), and mammals (Hersteinsson \& Macdonald 1992), with general trends of movement toward higher latitude or higher elevation. Thus, assessing the influence of future climates on species' current distribution patterns by uncovering stable areas and new potentially suitable areas is critical for biodiversity conservation in the context of global climate change.

() The authors 2015. Open Access under Creative Commons by Attribution Licence. Use, distribution and reproduction are unrestricted. Authors and original publication must be credited. Publisher: Inter-Research · www.int-res.com 
Estimations of future climates are based on several fundamental principles from physics, chemistry, and fluid mechanics. Climate models simulate the interaction between the atmosphere, ocean, land surface, and ice in 3-dimensional grids, and future climate variables are computed according to the interaction between factors in each grid, such as wind, heat transmission, radiation, and relative humidity (Easterling et al. 1997). The most frequently used climate models are coupled atmosphere-ocean Global Circulation Models (GCMs), recognized as effective tools for simulating the influence of increasing greenhouse gases on global climate (Solomon et al. 2007).

Ecological niche models (ENMs) are widely used in predicting species' potential distributions (Anderson et al. 2002, Peterson 2003, Peterson et al. 2007), and in this framework equilibrium status (Araujo \& Pearson 2005) and niche conservatism (Pearman et al. 2008) are 2 important assumptions. Species are assumed to be at equilibrium with the environment if they occur in all environmentally suitable areas whilst being absent from all unsuitable localities (Hutchinson 1957). ENMs also assume the species' ecological niche is conserved considerably over evolutionary time scales and especially over short-tomoderate time spans (Peterson et al. 1999, Peterson 2011). Under these 2 assumptions, ENMs can estimate a species' potential distribution with environmental conditions similar to occurrence sites within the study area by summarizing the relationship between the occurrence sites and associated environmental variable values, and projecting the model onto different study areas or the same study areas under different climate conditions (Hu \& Jiang 2011, Liu et al. 2011). Biotic factors are generally not included (Soberón \& Nakamura 2009); instead, climatic variables are typically the environmental data used in ENMs to model species' climatic niches (Broennimann et al. 2007), which represent the species' climatic requirements, and find climatically suitable areas (CSAs) in geographic space (Lee et al. 2012). Several ENM algorithms that use machine learning and multivariate statistics have been developed, such as Maximum Entropy (Maxent; Phillips et al. 2004), Ecological Niche Factor Analysis (ENFA; Hirzel et al. 2001), and Genetic Algorithm for Ruleset Prediction (GARP; Stockwell et al. 2006). Maxent is regarded as consistently competitive with the best performing methods (Elith et al. 2006, Phillips \& Dudik 2008).

Reeves's pheasant Syrmaticus reevesii is endemic to China, and the male pheasant is characterized by beautiful long tail feathers. Its historic distribution was broad and widespread throughout central and northern China; because of hunting and deforestation (Xu et al. 1991, 1995, McGowan et al. 1995, Zheng \& Wang 1998), its distribution is now restricted to a smaller area in the Henan, Anhui, Shaanxi, Hubei, and Guizhou provinces of central China in recent years (Collar et al. 2001). The northern populations that resided in Hebei and Shanxi are regarded as extinct, as the last presence record was in October 1953 (Collar et al. 2001). Since 1950, Reeves's pheasant populations have declined dramatically. The International Union for the Conservation of Nature (IUCN) has classified the species as Vulnerable (BirdLife International 2012), and Zhou et al. (2014) recommended a categorization of this species as Endangered according to the most updated survey. With the aim of providing meaningful information for the conservation of this species in the perspective of climate change, we used ENMs to (1) estimate the current CSA of $S$. reevesii and compare the current CSA with the species' historical range (e.g. county-level records) and land-cover requirements; (2) reveal general patterns of CSA variation under climate change by projecting the niche model onto future climate layers; and (3) assess the vulnerability of nature reserves for $S$. reevesii under climate change, information that may aid the conservation of this species.

\section{MATERIALS AND METHODS}

\section{Species' occurrence data}

The occurrence data for Syrmaticus reevesii in our study were gathered from recent surveys and literature. We obtained 49 points (Fig. 1) with GPS coordinates collected during surveys across 5 provinces (Henan, Hubei, Shaanxi, Guizhou, and Yunnan) in China (Xu et al. 2006). To increase our sample size, we identified additional locations from the literature (Collar et al. 2001, Xie 2001), including centroid coordinates of 16 nature reserves and 1 park in which the species had been recorded present (Supplement 1 at www.int-res.com/articles/suppl/n028p019_supp.pdf). To reduce discrepancy between locational uncertainty and the resolution of climatic layers, we excluded 5 of the 16 nature reserves that were larger than $400 \mathrm{~km}^{2}(20 \times 20 \mathrm{~km}$, which is approximately the size of 1 grid cell in the climatic layers). To reduce sampling bias (Boria et al. 2014), we excluded multiple occurrence points that fell in the same grid cell. 


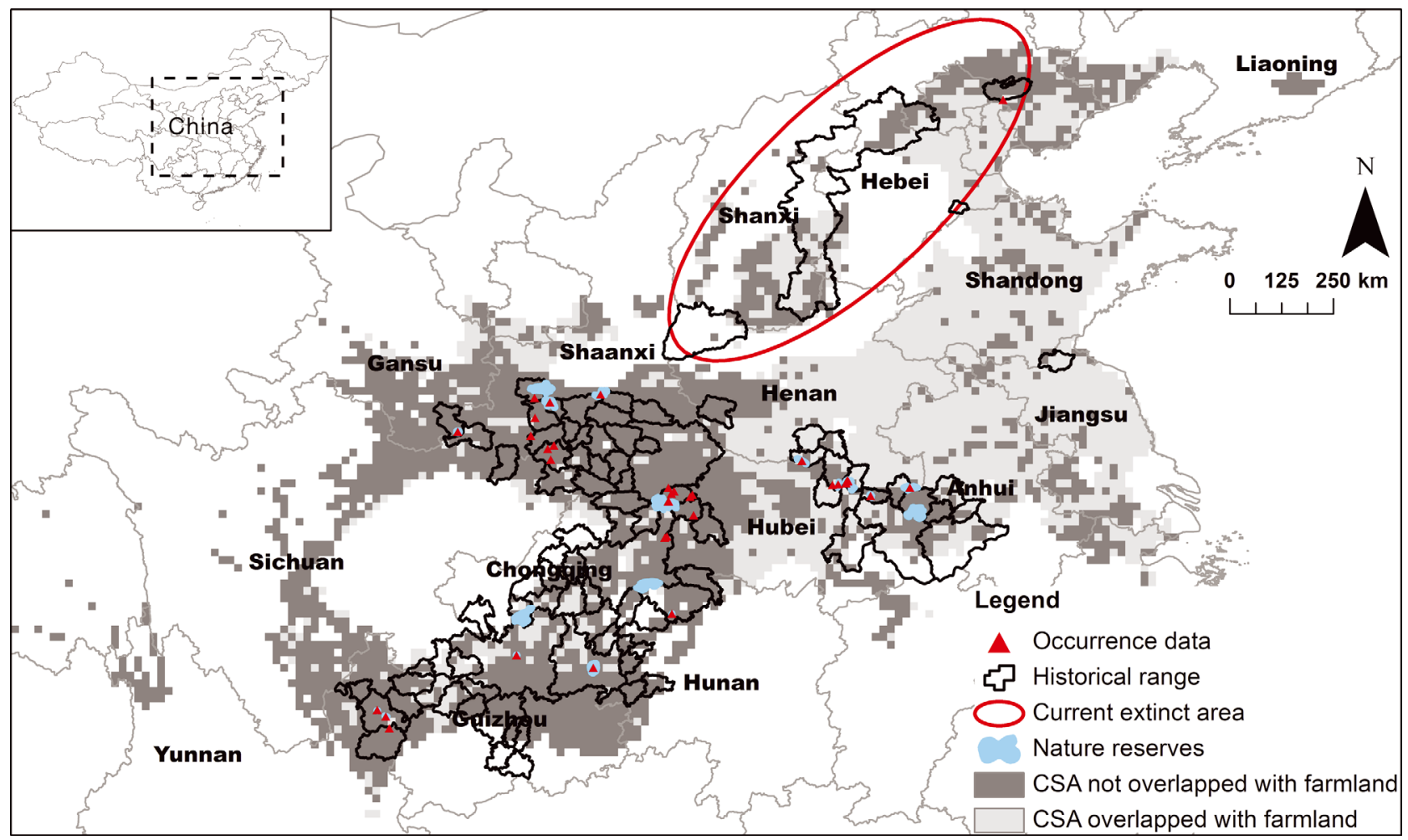

Fig. 1. Historical range, occurrence points of Syrmaticus reevesii used in ecological niche modeling, climatically suitable area (CSA) at present in relation to farmland, and nature reserves with known $S$. reevesii records

Finally, 29 geographically unique points were used to train the ENM. The precise distribution information in the literature was scarce, possibly because of the rapid distributional reduction of $S$. reevesii in the last century, combined with the fact that few detailed surveys were carried out prior to the reduction in distribution. The occurrence data we used may not precisely represent the historical range of $S$. reevesii, but, to our knowledge, include all existing occurrence information appropriate for this study.

\section{Environmental variables}

We used present-day climatic data to train the ENM and projected the model onto future climatic layers. We chose 10 arc-minutes (about $20 \mathrm{~km}$ ) as the spatial resolution for all environmental layers, aiming to model the climatic requirements at a relatively broad spatial scale and account for the uncertainties associated with occurrence data and climate layers. We downloaded 19 present-day (1950-2000) bioclimatic variables from WorldClim (www.worldclim.org; Hijmans et al. 2005; Table S1 in Supplement 2 at www.int-res.com/articles/suppl/ n028p019_supp.pdf) that are biologically meaningful and widely used in ecological niche modeling (Shafer et al. 2001, Thuiller et al. 2006, Liu et al. 2011, Lee et al. 2012). The future climatic data were downloaded at the same resolution from a Global Climate Model data portal (www.ccafsclimate.org). The future climatic data were downscaled (Ramirez-Villegas \& Jarvis 2010) from Hadley Centre Coupled Model Version 3 (HADCM3), which is one of the GCMs used in the Fourth Assessment Report of the IPCC. We chose a series of future temporal ranges (2010-2039, 2040-2069, and 2070-2099), each spanning $30 \mathrm{yr}$, and hereafter referred to as 2020, 2050, and 2080, respectively. We chose 3 different emission scenarios (a1b, a2, b1) described in the IPCC Special Report on Emission Scenarios (Nakicenovic et al. 2000) to mimic different warming trends as a function of future population growth, technology, and energy use. The most obvious difference between the 3 emission scenarios is the increased average annual temperature at the end of the $21^{\text {st }}$ century: the a2 emission scenario projects a larger temperature increase (about $3.4^{\circ} \mathrm{C}$ ) than a1b $\left(2.8^{\circ} \mathrm{C}\right)$ and $\mathrm{b} 1$ $\left(1.8^{\circ} \mathrm{C}\right)$. 


\section{Ecological niche modeling}

We built ecological niche models using the Maxent algorithm (Version 3.3.3k; Phillips et al. 2004) that estimates a species' potential distribution by computing the maximum likelihood using Gibbs probability distribution with the maximum entropy subject to a set of constraints derived from environmental variables. Considering the importance of species' accessibility in ecological niche modeling (Soberón \& Peterson 2005), there is a high probability that the model may underestimate the potential distribution if trained on a large background area, which may include a CSA from which the species is absent because of inaccessibility or biotic factors (e.g. extinct because of human activities), thus providing a 'false negative signal' for Maxent (Anderson \& Raza 2010). Therefore, we used a smaller background area-specifically, buffers around the occurrence data, an approach that can generate a more realistic prediction (Anderson \& Raza 2010)3-and we assumed that $S$. reevesii was in equilibrium with the environment in the buffered background area. We built a 1 decimal degree (about $120 \mathrm{~km}$ ) radius buffer around the occurrence data to delineate the background area - a relatively broad estimation of the area that $S$. reevesii can disperse into and in which it may acquire equilibrium status. We used present climatic layers within the buffered background area to build the model and projected the model onto present and future climatic layers. To identify geographic areas where the environmental values in the projection dataset are outside the range of values in the buffered background area, Maxent employs a multivariate environmental similarity surface analysis (MESS; Elith et al. 2010). We masked out these outlier areas (negative values in MESS map output), where the prediction was questionable and the species' distribution could be limited by the environmental conditions that were not available in the buffered background area (Elith et al. 2010).

Because highly correlated predictor variables may lead to model overfitting, for model building we selected a subset of the 19 bioclimatic variables with a correlation coefficient of $|r|<0.7$, as it has been shown that model distortion by collinearity of variables could be better avoided at this threshold (Dormann et al. 2013). We built a Pearson correlation matrix for the 19 bioclimatic variables based on the buffered background area, and found that 1 variable was usually highly correlated with multiple variables. We drew a network diagram using raster (Hijmans 2014) and igraph (Csardi \& Nepusz 2006) libraries in R to facili- tate the variable selection. In the network diagram, highly correlated variables $(|r| \geq 0.7)$ were linked by lines Fig. S1 in Supplement 2) and were clustered together. When selecting variables that were not linked in the network diagram, we prioritized extreme variables instead of average variables among the clustered variables (e.g. we selected maximum temperature of the warmest month instead of annual mean temperature), assuming that extreme variables are more likely to be limiting factors for the species. Using these procedures we retained 6 variables: isothermality (bio3), temperature seasonality (bio4), maximum temperature of the warmest month (bio5), minimum temperature of the coldest month (bio6), precipitation of the wettest quarter (bio16), and precipitation of the driest quarter (bio17). Since projecting the model onto environmental datasets with different collinearity should be avoided (Dormann et al. 2013), we compared the correlation matrix of the 6 variables in the training region to the average of the correlation matrices of present and future climate layers in the projected area (Tables S2 \& S3 in Supplement 2). The highest absolute change of $\mathrm{r}$ was 0.3 for bio4 and bio17, and $r$ increased above the 0.7 threshold for 2 pairs of variables $(-0.78$ for bio3 and bio4; 0.71 for bio16 and bio17; Supplement 2). Variation among correlation matrices of different environmental datasets is unavoidable; we regarded the low amount of variation in our study as having a small influence on model projections.

We trained the Maxent model with all species' occurrence points (29) and 6 bioclimatic variables for current climate conditions, with all grid cells (1514) in the buffered background area as background points. Linear, quadratic, and hinge features were used based on the number of occurrence points (Elith et al. 2011), and the regularization parameter was set to default. Maxent algorithm searches for solutions until a maximum of 500 iterations is reached or the increment of model accuracy is negligible, and the best model is retained (Phillips et al. 2004). We projected this model onto the present and future bioclimatic layers. We converted the original Maxent continuous output format, with values ranging from 0 to 1 , to binary form ( $1=$ suitable and $0=$ unsuitable) using the lowest training presence threshold (Phillips et al. 2006, Pearson et al. 2007). The areas classified as climatically suitable were at least as suitable as the occurrence points, a conservative approach of zero omission error (no known occurrences predicted absent) to classifying the prediction grid cells into suitable and unsuitable (Pearson et al. 2007). To validate the model, we calculated area under curve 
(AUC) of receiver operating characteristic (ROC), based on the sensitivity (1 - omission error) and $1-$ specificity (fractional predicted area) (Phillips et al. 2006). The AUC value was calculated in 2 ways, first with all occurrence points for training and second by running cross validation with $80 \%$ for training and $20 \%$ for testing. We expected the AUC values to be $>0.5$, suggesting the ENMs were better than random (Swets 1979). However, the significance of using only ROC AUC to evaluate ENM is debatable (JimenezValverde 2012), so we included species' historical range as an additional way of evaluating the model.

\section{Historical range and land-cover}

We compiled information on the historical range of $S$. reevesii (Table S4 in Supplement 3 at www.intres.com/articles/suppl/n028p019_supp.pdf), aiming to represent the overall distribution of $S$. reevesii using county-level and mountain-area records (Collar et al. 2001, Xie 2001) that were not included as occurrence data in the ENM because of the discrepancy between locational uncertainty and the resolution of climatic layers. The mountain-area records partly overlapped with county-level records, except for Taihang Mountain and Zhongtiao Mountain in the Shanxi province. We did not find any precise geographical distribution records for Taihang Mountain or Zhongtiao Mountain, so we manually drew general boundaries of the 2 mountains. The historical range included 9 cities, 78 counties, and 2 mountains, spanning 13 provinces, an extent that may be broader than the recorded distribution of the species. We used historical range as independent information to evaluate the ENM, and we expected the ENM to cover the historical range.

Vegetation type is very important for the hiding and foraging behaviors of $S$. reevesii (Zheng 1978). A recent study showed that, at a relatively broad scale, mixed forest, mature fir plantation, and shrubby vegetation were preferred by $S$. reevesii, whereas farmland was avoided (Xu et al. 2007). We did not use land-cover to train the ENM because we aimed to generate the CSA rather than the actual distribution of the species and because we used several time frames for which land-cover data are not available. However, we assumed that the species' vegetation requirements would be represented by the climatic requirements, so we investigated whether the landcover of the present CSA matched the land-cover of occurrence points. We downloaded the Global Land Cover 2000 database (Wu et al. 2003) and overlapped it with our occurrence data and the present CSA to determine whether the present CSA included the land-cover requirements of $S$. reevesii. To minimize uncertainty, we only used the GPS occurrence points from surveys and extracted the land-cover type from the Global Land Cover map at the original resolution $(1 \mathrm{~km})$. To determine the land-cover of CSA, we resampled the original Global Land Cover map to the same resolution as the bioclimatic layers (10 arcminute), retaining the most frequent land-cover type within each 10 arc-minute grid cell, and overlapped the transformed Global Land Cover map with CSA.

To further test the robustness of our model, we built random models trained with the same but randomly selected number of occurrence points and the same set of climatic variables as that used to generate the present CSA. All the other modeling procedures were the same as those used in generating the present CSA. We generated 100 random models and calculated the percentage of each land-cover type in the CSAs of the random models using the same method as we did for the present CSA. Finally, we used the 1-way $t$-test to determine if the percentage of each land-cover type was higher or lower in the present CSA than in the random models, and whether such land-cover types matched the land-cover types of occurrence points.

\section{Assessment of CSA changes with future climates}

To assess the changing tendency of CSAs in the future, we focused on the geographic attributes of CSAs including area, average and range of longitude, latitude, altitude, and centroid position. By comparing the CSAs at present and in the future, we estimated the changes of the CSAs in a time series. To assess the influence of climate change on CSAs in nature reserves, we overlapped CSAs with the polygons of nature reserves and calculated the percentage of area climatically suitable within each nature reserve. Then, we calculated the changes of the percentages across time, based on which we inferred the vulnerability of the nature reserves to climate change from the perspective of protecting $S$. reevesii.

\section{RESULTS}

\section{CSAs at present}

The model obtained with the 6 bioclimatic variables and all occurrence data had an AUC value of 0.8 ; when validating the model, the average training 
AUC value was $0.81(\mathrm{SD}=0.032)$ and the testing AUC value was $0.73(\mathrm{SD}=0.118)$. The lowest training presence threshold was 0.111 , with which we classified the model prediction grid cells into suitable and unsuitable. After masking out the outlier cells (negative values in MESS), about $13 \%$ of projection grid cells were predicted as CSA under present climatic conditions, mostly located in central and north-central China (Fig. 1).

The CSA fully or partly covered the polygons of 9 cities, 76 counties, and 2 mountains in the historical range, with the exception of 2 counties (Huishui County and Pingtang County) in Guizhou Province. The present areas of extinction in northern China were also covered by the CSA, such as Zhongtiao and Taihang mountains. However, our model also predicted climatically suitable regions that had no historical records but high percentages of farmland: most of Shandong and Jiangsu provinces and the western Liangning province. By excluding areas covered by farmland from the present CSA, the areas outside the historical range were greatly reduced and the remaining CSA better matched the historical range (Fig. 1).
We acquired the land-cover type of both the occurrence points and the CSA (Table 1). The points at which Syrmaticus reevesii occurred (occurrence points) were located in 7 types of land-cover: needleleaved evergreen forest, broad-leaved evergreen forest, broad-leaved deciduous forest, bush, sparse woods, alpine and sub-alpine meadow, and slope grassland. The present CSA covered 16 land-cover types: $53 \%$ of the CSA grid cells had the same landcover types as the occurrence points, $44 \%$ were farmland, and $3 \%$ had different land-cover types (besides farmland) than the occurrence points. The 1 -way $t$ test showed that the percentages of 14 land-cover types were significantly different $(\mathrm{p}<0.05$; Table 1$)$ between the present CSA and the random models. The percentages of 10 land-cover types were significantly higher $(\mathrm{p}<0.05$; Table 1$)$ in the present CSA than in the random models, while 6 of the 10 landcover types matched the land-cover types of the occurrence points. The percentages of 4 land-cover types were significantly lower $(p<0.001$; Table 1$)$ in the present CSA than in the random models, while 3 of the 4 land-cover types did not match land-cover types of the occurrence points.

Table 1. Overview of land-cover types in climatically suitable area (CSA) for Syrmaticus reevesii. The percentage of each land-cover type in present CSAs and the percentage of each land-cover type in the random models are given $(0 \%$ if not otherwise specified). (+) Significantly higher percentages in present CSA than in random models $(1$-way $t$-test, $\mathrm{p}<0.05) ;(-)$ significantly lower percentages in present CSA than in the random models; otherwise, no significant difference or noncomparable; $\left({ }^{*}\right)$ coincidence of occurrence points and land-cover types

\begin{tabular}{|c|c|c|c|c|}
\hline Land-cover class & $\begin{array}{l}\text { Percentage in the } \\
\text { present CSA }\end{array}$ & $\begin{array}{l}\text { Percentage in the random } \\
\text { models (mean } \pm \text { SD) }\end{array}$ & $t$-test & $\begin{array}{l}\text { Occurrence } \\
\text { points }\end{array}$ \\
\hline Needle-leaved deciduous forest & & $1.66 \pm 2.80$ & & \\
\hline Needle-leaved evergreen forest & 17.83 & $8.64 \pm 3.94$ & + & * \\
\hline Broad-leaved evergreen forest & 5.74 & $2.72 \pm 1.25$ & + & * \\
\hline Broad-leaved deciduous forest & 11.06 & $5.53 \pm 3.11$ & + & * \\
\hline Bush & 8.29 & $3.83 \pm 1.50$ & + & * \\
\hline Sparse woods & 0.68 & $0.45 \pm 0.91$ & + & * \\
\hline Seaside wet lands & 0.11 & $0.11 \pm 0.35$ & & \\
\hline Alpine and sub-alpine meadow & 3.65 & $10.25 \pm 3.92$ & - & * \\
\hline Slope grassland & 6.00 & $1.92 \pm 0.64$ & + & * \\
\hline Plain grassland & 0.24 & $4.38 \pm 1.32$ & - & \\
\hline Desert grassland & & $5.91 \pm 2.03$ & & \\
\hline Meadow & 0.26 & $6.43 \pm 3.59$ & - & \\
\hline City & 0.07 & $0.04 \pm 0.01$ & + & \\
\hline River & 1.06 & $0.47 \pm 0.16$ & + & \\
\hline Lake & 0.88 & $0.62 \pm 0.20$ & + & \\
\hline Swamp & 0.31 & $0.28 \pm 0.16$ & & \\
\hline Glacier & 0.04 & $1.08 \pm 0.54$ & - & \\
\hline Bare rocks & & $2.02 \pm 0.66$ & & \\
\hline Gravels & & $7.33 \pm 2.50$ & & \\
\hline Desert & & $5.34 \pm 2.49$ & & \\
\hline Farmland & 43.79 & $17.83 \pm 6.01$ & + & \\
\hline Alpine and sub-alpine plain grass & & $6.81 \pm 3.34$ & & \\
\hline Mosaic of cropping & & $0.29 \pm 0.46$ & & \\
\hline Forest mosaic and degraded forest & & $0.08 \pm 0.11$ & & \\
\hline
\end{tabular}




\section{Changes in CSAs under future climate scenarios}

Using 3 emission scenarios (a1b, a2, and b1), we obtained 3 series of CSAs (Fig. 2, Table 2) for each future time frame (2020, 2050, and 2080). Compared with the present CSA, areas of CSAs decreased in the future under all emission scenarios (Fig. 3); the number of newly gained grid cells (suitable only in the future) was lower than that of the lost grid cells (suitable only in the present). The area of CSA decreased by $19 \%$ $(\mathrm{SD}=0.12)$ in $2020,45 \%(\mathrm{SD}=0.09)$ in 2050 , and $58 \%$ ( $\mathrm{SD}=0.05$ ) in 2080 , on average, among the 3 emission scenarios. The geographic centroids of CSAs shifted southwest in 2020 and northwest in 2050 and 2080 (Table 2). Specifically, the average shift, over the 3 emission scenarios, was southward 0.64 degrees $(\mathrm{SD}=0.33)$ and westward 0.63 degrees $(\mathrm{SD}=0.53)$ in 2020 , northward 0.45 degrees $(\mathrm{SD}=0.43$ ) and westward 2.81 degrees $(\mathrm{SD}=2.11)$ in 2050, and northward 0.26 degrees $(\mathrm{SD}=0.16)$ and westward 7.11 degrees $(\mathrm{SD}=0.26)$ in 2080. The northern limits of the future CSAs moved slightly southward and the southern ones moved northward (Table 2), resulting in a latitudinal range reduction under all emission scenarios. The western limits of all CSAs moved further westward than the eastern ones (Table 2), which resulted in a longitudinal range extension for all emission scenarios. The average, minimum, and maximum altitudes of CSAs increased or remained the same under future climate scenarios, with one exception, under b1 emission scenario in 2020 (Table 2); the average altitude of CSAs, among the 3 emission scenarios, increased by $82.96 \mathrm{~m}(\mathrm{SD}=83.44)$ in $2020,783.26 \mathrm{~m}(\mathrm{SD}=$ $453.8)$ in 2050 , and $1752.4 \mathrm{~m}(\mathrm{SD}=482.66)$ in 2080.

\section{Nature reserves and CSAs}

By overlapping the polygons of nature reserves with CSAs at present and in the future, we found that the present CSA covered all nature reserves with species' records, but inside each nature reserve CSAs changed differently under the future climate scenarios (Table 3, Fig. 2). Among 18 nature reserves, CSAs fully covered $(100 \%) 2$ nature reserves (Longshengou and Foping) under all emission scenarios, whereas in 3 other nature reserves (Shennongjia, Taibaishan, and Niubeiliang) the percentages of CSAs declined under some emission scenarios but never completely to zero. In the remaining 13 nature reserves the percentages of CSAs decreased considerably or completely, under at least one emission scenario.

\section{DISCUSSION}

Our models showed that the present CSA covered most of the current and extinct distribution of Syrmaticus reevesii. Additional areas outside the historical range were also predicted as climatically suitable, but these areas have high percentages of farmland and a long history of agricultural practices. Anthropogenic factors, including poisoning by farmers, were the main reasons for population declines of S. reevesii (Xu et al. 1991, McGowan et al. 1995, Xu et al. 1995, Zheng \& Wang 1998, Zhou et al. 2014). Thus, we expect $S$. reevesii to be absent from the predicted climatically suitable areas overlapping with farmlands. Excluding farmland, the present CSA generally matched the land-cover requirements of $S$. reevesii. Under climate change, the CSAs decreased and became more fragmented. The average altitude of CSAs increased with projected temperature increases in the future, and the geographic centroids of CSAs mainly shifted northwestward. The nature reserves located in the eastern and southern part of the species' current distribution were more vulnerable to climate change than nature reserves located in the central part (e.g. Shaanxi province), since, under future climate scenarios, in the former nature reserves the CSAs mainly decreased, whereas in the later nature reserves the CSAs generally remained the same.

\section{ENM for a vulnerable species}

Ecological niche models have been applied to species with few or limited occurrence data (Godown \& Peterson 2000, Weinsheimer et al. 2010, Hu \& Liu 2014). However, the difficulties in such situations come from limited occurrence data that only represent the current distribution instead of the extinct distribution. To train the ENM with as much distribution information as possible, we identified additional locations of nature reserves and parks that were smaller than the grid size of the climatic layers. We spatially filtered (Boria et al. 2014) occurrence data that fell in the same grid cells to reduce model overfitting on current distribution information. Additionally, inclusion of areas from the extinct distribution as background samples in Maxent would represent false negative information and affect discrimination of a species' climatic requirements (Anderson \& Raza 2010). To avoid inclusion of false negative samples, we limited the background to buffers around known presences. When projecting ENMs onto other geo- 


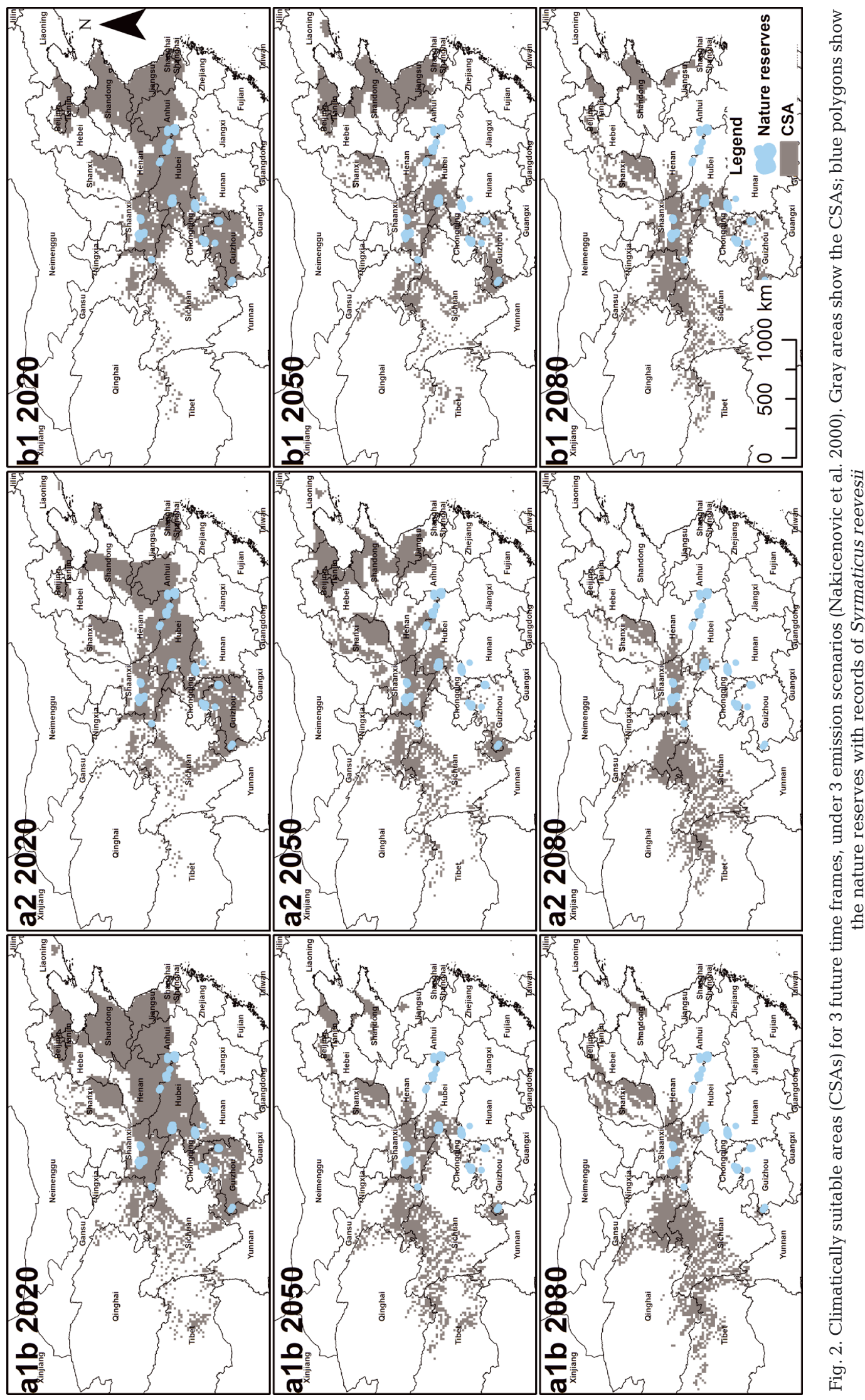


Table 2. Geographic attributes of climatically suitable areas (CSAs) for Syrmaticus reevesii under present and future climate conditions

\begin{tabular}{|c|c|c|c|c|c|c|c|c|c|c|c|c|c|}
\hline \multirow[t]{2}{*}{ Model } & \multirow{2}{*}{$\begin{array}{c}\text { Average } \\
\text { annual } \\
\text { temp. } \\
\left({ }^{\circ} \mathrm{C}\right)\end{array}$} & \multirow{2}{*}{$\begin{array}{l}\text { No. of } \\
\text { CSA } \\
\text { grid } \\
\text { cells }\end{array}$} & \multicolumn{2}{|c|}{$\begin{array}{l}\text { Centroid of CSAs } \\
\text { (decimal degrees) }\end{array}$} & \multicolumn{3}{|c|}{$\begin{array}{l}\text { Latitude extent of CSAs } \\
\text { (decimal degrees) }\end{array}$} & \multicolumn{3}{|c|}{$\begin{array}{l}\text { Longitude extent of CSAs } \\
\text { (decimal degrees) }\end{array}$} & \multicolumn{3}{|c|}{ Altitude of CSAs (m) } \\
\hline & & & $\begin{array}{l}\text { Longitude } \\
\qquad\left({ }^{\circ} \mathrm{E}\right)\end{array}$ & $\begin{array}{l}\text { Latitude } \\
\left({ }^{\circ} \mathrm{N}\right)\end{array}$ & $\begin{array}{l}\text { Southern } \\
\text { limit }\end{array}$ & $\begin{array}{l}\text { Northern } \\
\text { limit }\end{array}$ & Range & $\begin{array}{c}\text { Eastern } \\
\text { limit }\end{array}$ & $\begin{array}{l}\text { Western } \\
\text { limit }\end{array}$ & Range & Average & Lowest & Highest \\
\hline Present & 6.48 & 4575 & 111.88 & 32.79 & 24.74 & 42.90 & 18.17 & 91.03 & 130.70 & 39.67 & 767.93 & -2 & 4009 \\
\hline $\mathrm{a} 1 \mathrm{~b} / 2020$ & 7.73 & 4262 & 111.41 & 32.98 & 24.74 & 42.57 & 17.83 & 78.86 & 130.53 & 51.67 & 914.05 & -2 & 4768 \\
\hline $\mathrm{a} 1 \mathrm{~b} / 2050$ & 9.49 & 2078 & 106.44 & 33.37 & 26.24 & 42.57 & 16.33 & 78.86 & 130.53 & 51.67 & 2154.12 & 0 & 4788 \\
\hline $\mathrm{a} 1 \mathrm{~b} / 2080$ & 10.80 & 2066 & 103.86 & 33.66 & 26.40 & 42.74 & 16.33 & 78.53 & 130.53 & 52.00 & 2823.72 & 1 & 5108 \\
\hline a2/2020 & 7.67 & 3178 & 111.00 & 32.18 & 24.90 & 42.57 & 17.67 & 78.86 & 130.53 & 51.67 & 905.65 & 0 & 4748 \\
\hline a2/2050 & 9.09 & 2876 & 110.41 & 34.29 & 25.90 & 42.57 & 16.67 & 78.86 & 130.53 & 51.67 & 1360.36 & -2 & 4788 \\
\hline a2/2080 & 11.13 & 1674 & 103.46 & 33.29 & 27.07 & 42.57 & 15.50 & 78.53 & 130.53 & 52.00 & 2898.17 & 2 & 5171 \\
\hline b1/2020 & 7.47 & 3740 & 112.27 & 32.63 & 25.24 & 42.57 & 17.33 & 79.03 & 130.53 & 51.50 & 732.99 & -2 & 4762 \\
\hline b1/2050 & 8.50 & 2579 & 111.31 & 33.41 & 25.90 & 42.57 & 16.67 & 78.86 & 130.53 & 51.67 & 1139.09 & -2 & 4788 \\
\hline b1/2080 & 9.44 & 2083 & 107.95 & 33.55 & 26.24 & 42.57 & 16.33 & 78.86 & 130.53 & 51.67 & 1839.12 & -2 & 4857 \\
\hline
\end{tabular}

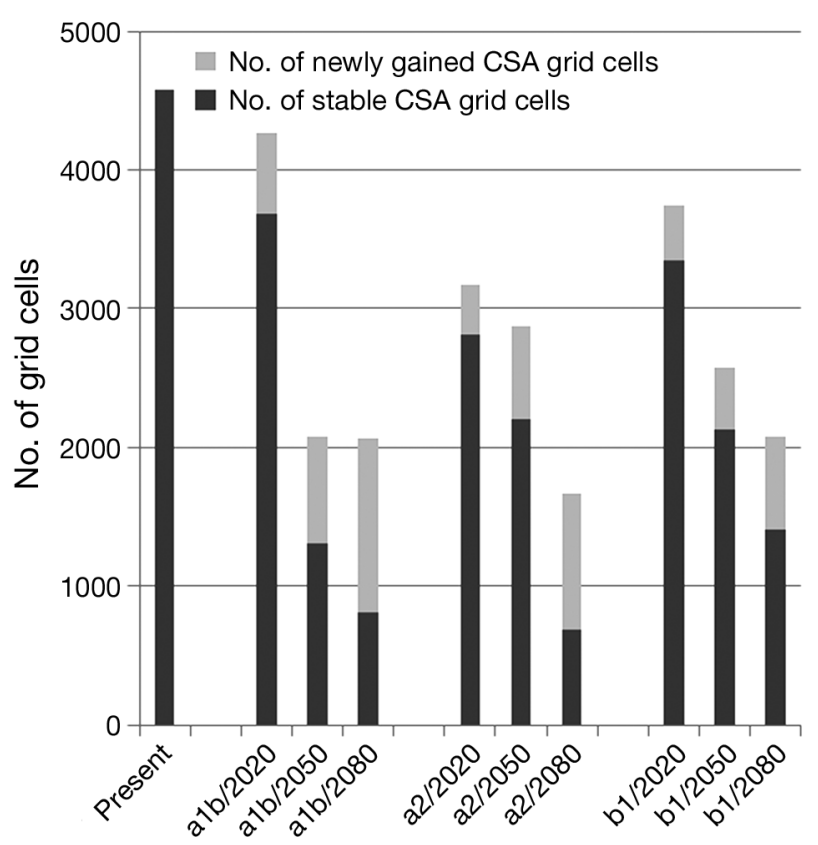

Fig. 3. Comparison of number of grid cells of climatically suitable areas (CSAs) for Syrmaticus reevesii at present and in the future. Black: stable CSA (suitable at present and in the future); gray: newly gained CSA (not suitable at present but suitable in the future)

graphic regions or future climates, the variation of the correlation matrices of variables represents a drawback. This issue has been brought to attention recently (Dormann et al. 2013), but is rarely reported in similar studies. We found a slight shift of the correlation matrices between training and projecting regions (Supplement 2) and regarded it as acceptable. The models performed well, as shown by consistent training and testing of AUC values across models, but they may have been penalized by the evaluation method for overpredicting with a rela- tively small background area. However, such overprediction should not be penalized by the evaluation method (Jimenez-Valverde 2012) when the goal is to estimate a vulnerable species' CSA rather than the actual distribution. The lowest training presence threshold was chosen, because omission error is weighted more than the commission error for models estimating species' potential distribution (Anderson et al. 2003, Peterson et al. 2008a), and a higher threshold may limit the prediction and underestimate species' climatic requirements that are similar to those of the omitted occurrence points. Therefore, we agreed with the argument that the lowest training presence threshold was a conservative way of estimating the potential distribution relative to the actual distribution (Pearson et al. 2007); especially when modeling a vulnerable species with limited occurrence data, a higher threshold would likely 'underpredict' the potential suitable areas.

\section{Present CSA, historical range, and land-cover}

Using occurrence data and bioclimatic variables, we estimated CSAs at present and in the future. The present CSA covered a broad area in central and north-central China, and generally ranged from 24.74 to $42.9^{\circ} \mathrm{N}$ and 91.03 to $130.7^{\circ} \mathrm{E}$. The present CSA covered both current and extinct distributions: 83 of the 85 historical counties and cities were fully or partly covered, and the 2 extinct mountain ranges were also partly covered. We consider our distributional estimation representative of the climatic requirements of $S$. reevesii for 3 reasons. First, the extinctions in Taihang Mountain and Zhongtiao Mountain were mainly caused by human activities, 
Table 3. Percentage of climatically suitable area (CSA) for Syrmaticus reevesii within each nature reserve under present and future climate conditions. A value of 1 means the nature reserve is fully covered by climatically suitable area, whereas 0 means the nature reserve is not covered at all

\begin{tabular}{|c|c|c|c|c|c|c|c|c|c|c|c|c|c|c|c|c|c|c|}
\hline Model & 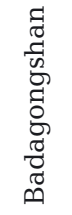 & 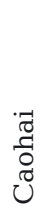 & 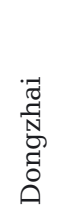 & 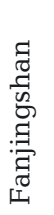 & 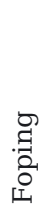 & 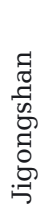 & 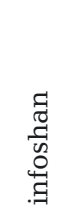 & 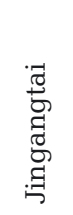 & 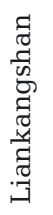 & 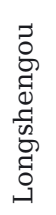 & 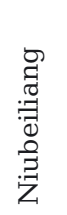 & 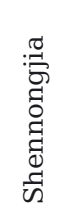 & 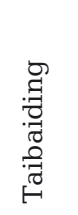 & 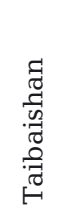 & 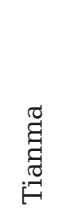 & 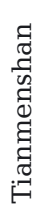 & $\begin{array}{l}\frac{\pi}{8} \\
\stackrel{0}{3} \\
\stackrel{9}{1}\end{array}$ & 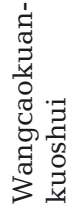 \\
\hline Present & 1 & 1 & 1 & 1 & 1 & 1 & 1 & 1 & 1 & 1 & 1 & 1 & 1 & 1 & 1 & 1 & 1 & 1 \\
\hline $\mathrm{a} 1 \mathrm{~b} / 2020$ & 1 & 1 & 1 & 1 & 1 & 1 & 0.83 & 1 & 1 & 1 & 1 & 1 & 1 & 0.75 & 0 & 1 & 1 & 0 \\
\hline $\mathrm{a} 1 \mathrm{~b} / 2050$ & 0.33 & 1 & 0 & 1 & 1 & 0 & 0.33 & 0.50 & 0 & 1 & 0.50 & 1 & 0.50 & 1 & 0 & 0 & 1 & 0 \\
\hline $\mathrm{a} 1 \mathrm{~b} / 2080$ & 0 & 0 & 0 & 0 & 1 & 0 & 0 & 0 & 0 & 1 & 1 & 0.33 & 0 & 1 & 0 & 0 & 1 & 0 \\
\hline a2/2020 & 0.67 & 1 & 1 & 1 & 1 & 1 & 1 & 1 & 1 & 1 & 1 & 1 & 1 & 0.75 & 0.67 & 0 & 1 & 0 \\
\hline a2/2050 & 0 & 1 & 0.50 & 1 & 1 & 1 & 0.33 & 0 & 1 & 1 & 0.50 & 1 & 1 & 1 & 0 & 0 & 1 & 0 \\
\hline a2/2080 & 0 & 0 & 0 & 0 & 1 & 0 & 0 & 0 & 0 & 1 & 1 & 0.50 & 0 & 1 & 0 & 0 & 0 & 0 \\
\hline b1/2020 & 0.67 & 1 & 1 & 1 & 1 & 1 & 1 & 1 & 1 & 1 & 1 & 1 & 1 & 0.88 & 0.67 & 0 & 1 & 1 \\
\hline b1/2050 & 0 & 1 & 0.50 & 1 & 1 & 1 & 0.50 & 0 & 1 & 1 & 1 & 1 & 1 & 0.88 & 0 & 0 & 1 & 0 \\
\hline b1/2080 & 0.67 & 1 & 0 & 1 & 1 & 0 & 0.33 & 0 & 0 & 1 & 1 & 1 & 0.50 & 1 & 0 & 0 & 1 & 0 \\
\hline
\end{tabular}

such as hunting and deforestation (Xu et al. 1991, 1995, McGowan et al. 1995, Zheng \& Wang 1998), which implies that these areas may still be climatically suitable for the species, and the present CSA covered areas in these extinction areas. Second, the present CSA was broader than the actual distribution and covered additional areas that had no historical records but had a high percentage of farmland and a long history of land use for agriculture. It is reasonable to expect the actual distribution to be a subset of the CSA, since restrictions of species' accessibility and species interactions were not included in the ENM. The approximation of CSA to historical range when farmland was excluded further suggested that the overpredicted areas were climatically suitable, but were not occupied by the species because of human activity. Third, vegetation type is very important for S. reevesii (Zheng 1978); thus, we considered land-cover as an independent factor to examine the prediction obtained via ENM. The survey occurrence points of $S$. reevesii corresponded to 7 land-cover types (Table 1), which were generally in accordance with habitat studies of $S$. reevesii (Zheng 1978, Xu et al. 2007). Excluding farmland, the land-cover types that matched land-cover types of occurrences constituted most of the present CSA, and the percentages of most of the matched land-cover types were statistically higher in the present CSA than in random models. The remaining 8 unmatched land-cover types only constituted a small portion of the present CSA, and 3 of these showed statistically lower percentages in the present CSA than in random models. This implied that the ENM captured the species' land-cover requirements represented in the present CSA. Xu et al. (2007) suggested that farmland was not preferred by $S$. reevesii; however, the percentage of farmland in the present CSA was significantly higher than that in the random models. One explanation for this result might be that some of the species' climatic requirements were similar to those of farmland, which would lead to geographic overlap with human land use. The negative anthropogenic effects, such as the use of poison to control crop seed foraging by Galliformes, continue to cause population declines of $S$. reevesii (Zhou et al. 2014). Therefore, we argue that the ENM successfully estimated climatically suitable areas for $S$. reevesii at present, but because of species' dispersal abilities and negative effects of anthropogenic activities, the actual distribution is only a subset of the CSA.

\section{Variations in future CSAs}

Comparing CSAs at present and in the future revealed several general patterns of temporal changes: the area of the CSAs decreased, the longitude range of the CSAs increased, the geographic centroids of the CSAs shifted northwest, and the average altitude of the CSAs increased. The patterns were similar among the 3 emission scenarios across time, but the changes of the CSAs in 2080 under a2 emission scenario were greater than those predicted under $\mathrm{a} 1 \mathrm{~b}$ or $\mathrm{b} 2$ emission scenarios, which was in accordance with the magnitude of annual temperature increase. The forecasted gains in CSAs were 
mainly located north and west of the present CSAs, and the lost CSAs were located south and east, which resulted in a northwest shift of geographic centroids of future CSAs. Importantly, the range of the CSAs generally increased in longitude, but the total area decreased, which suggests that the CSA may become more fragmented along latitude under climate change and the habitat fragmentation may be intensified. The present CSA is continuous in central China, but the actual distribution is divided into eastern and western regions (Collar et al. 2001) because of hunting and deforestation. The model predictions showed that the 2 regions would be separated by climatically unsuitable areas in the future, especially after 2050. The predictions of CSAs under climate change implied significantly negative effects for $S$. reevesii, thus calling for special attention to the recent proposal of updating the IUCN status of this species from Vulnerable to Endangered (Zhou et al. 2014).

While some studies showed that species' ranges would shift to higher latitudes (i.e. north in the Northern Hemisphere) under global warming (Parmesan et al. 1999, Thomas \& Lennon 1999, Hickling et al. 2006), other studies found that species may shift their distribution in different directions. For example, a drought gradient in central Africa, near the equator, may lead a species to a westward distributional shift, while species in southern Africa would likely move eastward (Thuiller et al. 2006). Our results showed that the geographic centroids of the CSAs mainly shifted northwest and the change was relatively greater in longitude than in latitude. One possible explanation is that, regardless of differences in methodological details (e.g. climate scenarios, ENM techniques, and species), the response of species to climate change may be dominated by regional climate gradients, which determine the distributional shift patterns. In China, a general southeast-northwest climatic gradient is present, mostly controlled by moist winds from the southeast coast to the northwest of the continent (Tchernia 1980). The changes in distributional patterns observed in our study were in agreement with this general climatic gradient (but see Hu \& Liu 2014 for a southwestward shift).

As climate becomes warmer in the future, it is presumed that many species will follow their climatic niche by moving to higher altitudes when possible. Hickling et al. (2006) found that besides birds and butterflies, 227 of 329 vertebrate and invertebrate animals, including dragonflies, spiders, amphibians, freshwater fish, mammals, wood lice, and beetles, have moveed to higher altitudes since 1960. Our re- sults corroborate this argument by showing that both average altitude and highest altitude of the CSAs increased dynamically across time under all emission scenarios. When annual average temperature increased by $1^{\circ} \mathrm{C}$, the average altitude of the CSAs increased about $263 \mathrm{~m}$ across all emission scenarios, which was much higher than the general lapse rate (Jacobson 2005), i.e. that temperature would decrease $1^{\circ} \mathrm{C}$ as altitude increased $156 \mathrm{~m}$. Thus, we propose that species' distribution shifts may not simply follow the temperature shift under global warming, and that precipitation and interaction of different climatic factors can possibly further augment the influence of global warming and determine future CSAs.

\section{Strategies for nature reserves}

We found that the present CSA covered all nature reserves with $S$. reevesii records, but that the changes in the percentage of each nature reserve covered by CSAs varied under different emission scenarios in the future. Some nature reserves (Tianma and Tianmenshan) were forecasted as climatically unsuitable for $S$. reevesii under several emission scenarios, and some (Longshengou and Foping) were climatically suitable under all emission scenarios (Table 3). The CSAs do not represent actual distributions, rather the premise for potential species' presence. Thus, the forecasted changes of CSAs within the nature reserve network may serve as a reference for conservation proposes. For the reserves which may become climatically unsuitable for Reeves's pheasant, a reassessment of reserve boundaries or even relocation could be considered; whereas, for the reserves that would maintain stable CSAs across time, the strengthening of management may be necessary. The areas predicted to be suitable among different emission scenarios at different time periods could be used as additional information when setting up new nature reserves for the conservation of this species. However, such decisions need to consider other species and conservation priorities, as well as human activities in the future, such as logging and hunting.

Acknowledgements. We appreciate the suggestions that $\mathrm{M}$. Pape and A. Loveless (Oklahoma State University) provided on this study. We thank Prof. Zhengwang Zhang (Beijing Normal University) for providing the survey data of Syrmaticus reevesii, and Jiangning Wang and Jinkui Cheng (Institute of Zoology, Chinese Academy of Sciences) for their help. We also thank the anonymous reviewers for their helpful comments. 


\section{LITERATURE CITED}

Anderson RP, Raza A (2010) The effect of the extent of the study region on GIS models of species geographic distributions and estimates of niche evolution: preliminary tests with montane rodents (genus Nephelomys) in Venezuela. J Biogeogr 37:1378-1393

> Anderson RP, Peterson AT, Gomez-Laverde M (2002) Using niche-based GIS modeling to test geographic predictions of competitive exclusion and competitive release in South American pocket mice. Oikos 98:3-16

Anderson RP, Lew D, Peterson AT (2003) Evaluating predictive models of species' distributions: criteria for selecting optimal models. Ecol Model 162:211-232

Araujo MB, Pearson RG (2005) Equilibrium of species' distributions with climate. Ecography 28:693-695

BirdLife International (2012) Syrmaticus reevesii. In: IUCN 2012. IUCN Red List of Threatened Species, Version 2012.2. www.iucnredlist.org (accessed 11 Apr 2013)

Boggs CL, Watt WB, Ehrlich PR (2003) Butterflies: ecology and evolution taking flight. University of Chicago Press, Chicago, IL

> Boria RA, Olson LE, Goodman SM, Anderson RP (2014) Spatial filtering to reduce sampling bias can improve the performance of ecological niche models. Ecol Model 275:73-77

Broennimann O, Treier UA, Muller-Scharer H, Thuiller W, Peterson AT, Guisan A (2007) Evidence of climatic niche shift during biological invasion. Ecol Lett 10:701-709

Collar NJ, Crosby R, Crosby MJ (2001) Threatened birds of Asia: the BirdLife International red data book. BirdLife International, Cambridge

Csardi G, Nepusz T (2006) The igraph software package for complex network research. InterJournal Complex Systems: 1695. www.igraph.org

> Dormann CF, Elith J, Bacher S, Buchmann C and others (2013) Collinearity: a review of methods to deal with it and a simulation study evaluating their performance. Ecography 36:27-46

Easterling DR, Horton B, Jones PD, Peterson TC and others (1997) Maximum and minimum temperature trends for the globe. Science 277:364-367

Elith J, Graham CH, Anderson RP, Dudik M and others (2006) Novel methods improve prediction of species' distributions from occurrence data. Ecography 29:129-151

Elith J, Kearney M, Phillips S (2010) The art of modelling range-shifting species. Methods Ecol Evol 1:330-342

> Elith J, Phillips SJ, Hastie T, Dudik M, Chee YE, Yates CJ (2011) A statistical explanation of MaxEnt for ecologists. Divers Distrib 17:43-57

> Godown ME, Peterson AT (2000) Preliminary distributional analysis of US endangered bird species. Biodivers Conserv 9:1313-1322

- Hersteinsson P, Macdonald DW (1992) Interspecific competition and the geographical distribution of red and Arctic foxes Vulpes vulpes and Alopex lagopus. Oikos 64:505-515

> Hickling R, Roy DB, Hill JK, Fox R, Thomas CD (2006) The distributions of a wide range of taxonomic groups are expanding polewards. Glob Change Biol 12:450-455

Hijmans RJ (2014) Raster: geographic data analysis and modeling. cran.r-project.org/web/packages/raster/ (accessed 1 Nov 2014)

> Hijmans RJ, Cameron SE, Parra JL, Jones PG, Jarvis A (2005) Very high resolution interpolated climate surfaces for global land areas. Int J Climatol 25:1965-1978

> Hirzel AH, Helfer V, Metral F (2001) Assessing habitatsuitability models with a virtual species. Ecol Model 145:111-121

> Hu J, Jiang Z (2011) Climate change hastens the conservation urgency of an endangered ungulate. PLoS ONE 6:e22873

Hu J, Liu Y (2014) Unveiling the conservation biogeography of a data-deficient endangered bird species under climate change. PLoS ONE 9:e84529

Hutchinson GE (1957) Concluding remarks. Cold Spring Harb Symp Quant Biol 22:415-427

Jacobson MZ (2005) Fundamentals of atmospheric modeling. Cambridge University Press, New York, NY

Jimenez-Valverde A (2012) Insights into the area under the receiver operating characteristic curve (AUC) as a discrimination measure in species distribution modelling. Glob Ecol Biogeogr 21:498-507

- Lee DN, Pape M, Van Den Bussche RA (2012) Present and potential future distribution of common vampire bats in the Americas and the associated risk to cattle. PLoS ONE $7: \mathrm{e} 42466$

> Liu X, Guo ZW, Ke ZW, Wang SP, Li YM (2011) Increasing potential risk of a global aquatic invader in Europe in contrast to other continents under future climate change. PLoS ONE 6:e18429

Markovic D, Carrizo S, Freyhof J, Cid N and others (2014) Europe's freshwater biodiversity under climate change: distribution shifts and conservation needs. Divers Distrib 20:1097-1107

McGowan PJK, Garson PJ and the WPA/BirdLife/SSC Pheasant Specialist Group (1995) Pheasants: status survey and conservation action plan 1995-1999. IUCN, Gland

Nakicenovic N, Alcamo J, Davis G, de Vries B and others (2000) Special report on emissions scenarios: a special report of Working Group III of the Intergovernmental Panel on Climate Change. Cambridge University Press, Cambridge

Parmesan C, Ryrholm N, Stefanescu C, Hill JK and others (1999) Poleward shifts in geographical ranges of butterfly species associated with regional warming. Nature 399:579-583

Pearman PB, Guisan A, Broennimann O, Randin CF (2008) Niche dynamics in space and time. Trends Ecol Evol 23:149-158

- Pearson RG, Raxworthy CJ, Nakamura M, Peterson AT (2007) Predicting species distributions from small numbers of occurrence records: a test case using cryptic geckos in Madagascar. J Biogeogr 34:102-117

> Peterson AT (2003) Predicting the geography of species' invasions via ecological niche modeling. Q Rev Biol 78:419-433

Peterson AT (2011) Ecological niche conservatism: a timestructured review of evidence. J Biogeogr 38:817-827

> Peterson AT, Soberón J, Sanchez-Cordero V (1999) Conservatism of ecological niches in evolutionary time. Science 285:1265-1267

Peterson AT, Pape M, Eaton M (2007) Transferability and model evaluation in ecological niche modeling: a comparison of GARP and Maxent. Ecography 30:550-560

Peterson AT, Pape M, Soberon J (2008a) Rethinking receiver operating characteristic analysis applications in ecological niche modeling. Ecol Model 213:63-72

Peterson AT, Stewart A, Mohamed KI, Araujo MB (2008b) 
Shifting global invasive potential of European plants with climate change. PLoS ONE 3:e2441

Phillips SJ, Dudik M (2008) Modeling of species distributions with Maxent: new extensions and a comprehensive evaluation. Ecography 31:161-175

Phillips SJ, Dudík M, Schapire RE (2004) A maximum entropy approach to species distribution modeling. In: Proceedings of the $21^{\text {st }}$ international conference on machine learning. ACM Press, Banff, AB, p 655-662

Phillips SJ, Anderson RP, Schapire RE (2006) Maximum entropy modeling of species geographic distributions. Ecol Model 190:231-259

Ramirez-Villegas J, Jarvis A (2010) Downscaling global circulation model outputs: the delta method decision and policy analysis working paper, No. 1. International Centre for Tropical Agriculture

Shafer SL, Bartlein PJ, Thompson RS (2001) Potential changes in the distributions of western North America tree and shrub taxa under future climate scenarios. Ecosystems 4:200-215

Soberón J, Nakamura M (2009) Niches and distributional areas: concepts, methods, and assumptions. Proc Natl Acad Sci USA 106:19644-19650

Soberón J, Peterson AT (2005) Interpretation of models of fundamental ecological niches and species' distributional areas. Biodivers Inform 2:1-10

Solomon S, Qin D, Manning M, Chen Z and others (2007) Climate change 2007: the physical science basis: contribution of Working Group I to the 4th assessment report of the Intergovernmental Panel on Climate Change. Cambridge University Press, Cambridge

Stockwell DRB, Beach JH, Stewart A, Vorontsov G, Vieglais D, Pereira RS (2006) The use of the GARP genetic algorithm and Internet grid computing in the Lifemapper world atlas of species biodiversity. Ecol Model 195: 139-145

Sturm M, Racine C, Tape K (2001) Climate change: increasing shrub abundance in the Arctic. Nature 411:546-547

Sun Q, Zhang Z (2000) The impact of climate warming on the distribution of Chinese birds. Chin J Zool 35:45-48

Swets JA (1979) ROC analysis applied to the evaluation of medical imaging techniques. Invest Radiol 14:109-121

Tchernia P (1980) Descriptive regional oceanography, Marine Series 3. Pergamon Press, Oxford

Thomas CD, Lennon JJ (1999) Birds extend their ranges northwards. Nature 399:213

Thomas CD, Cameron A, Green RE, Bakkenes M and others (2004) Extinction risk from climate change. Nature 427:145-148

Editorial responsibility: Michael Reed, Medford, Massachusetts, USA
Thuiller W, Broennimann O, Hughes G, Alkemade JRM, Midgley GF, Corsi F (2006) Vulnerability of African mammals to anthropogenic climate change under conservative land transformation assumptions. Glob Change Biol 12:424-440

Walther GR, Post E, Convey P, Menzel A and others (2002) Ecological responses to recent climate change. Nature 416:389-395

Weinsheimer F, Mengistu AA, Rödder D (2010) Potential distribution of threatened Leptopelis spp. (Anura, Arthroleptidae) in Ethiopia derived from climate and landcover data. Endang Species Res 9:117-124

Williams JW, Jackson ST, Kutzbach JE (2007) Projected distributions of novel and disappearing climates by 2100 AD. Proc Natl Acad Sci USA 104:5738-5742

Wu BF, Xu WT, Huang HP, Yan CZ (2003) The land-cover map for China in the year 2000. http://bioval.jrc.ec. europa.eu/products/glc2000/products.php (accessed 3 May 2015)

Xie Y (2001) China Species Information System (CSIS). http:// monkey.ioz.ac.cn/bwg-cciced/english/cesis/csispage.htm (accessed 11 Apr 2013)

> Xu JL, Zhang XH, Zhang ZW, Zheng GM, Ruan XF, Zhang $\mathrm{K}$, Xi B (2006) Home range and habitat use of male Reeves's pheasant (Syrmaticus reevesii) during winter in Dongzhai National Nature Reserve, Henan Province, China. Front Biol China 1:174-181

> Xu JL, Zhang ZW, Zheng GM, Zhang XH, Sun QH, McGowan PJK (2007) Home range and habitat use of Reeves's pheasant (Syrmaticus reevesii) in the protected areas created from forest farms in the Dabie Mountains, central China. Bird Conserv Int 17: 319-330

Xu WS, Wu ZK, Li ZM (1991) Reeves's pheasant (Syrmaticus reevesii). In: Lu TC, Liu RS, He FQ (eds) The rare and endangered gamebirds in China. Fujian Science and Technology Press, Fuzhou, p 328-338

Xu YG, Yin ZH, Zhang KY, Zhang XF, Gao ZJ (1995) The status of Reeves's pheasant at Dongzhai of Henan province and suggestion for conservation. Sinozoologia 12:335-341

Zheng ZX (1978) Aves, Vol. 4: Galliformes. Fauna Sinica. Science Press, Beijing

Zheng GM, Wang QS (1998) China red data book of endangered animals (Aves). Science Press, Beijing

- Zhou C, Xu J, Zhang Z (2014) Dramatic decline of the Vulnerable Reeves's pheasant Syrmaticus reevesii, endemic to central China. Oryx FirstView:1-6, doi:10.1017/S003 0605313000914

Submitted: May 16, 2014; Accepted: January 15, 2015 Proofs received from author(s): May 4, 2015 